PCBs in cod (Gadus morhua), flounder (Platichthys flesus), blue mussel (Mytilus edulis) and brown shrimp (Crangon crangon) from the Belgian continental shelf: relation to biological parameters and trend analysis.

Patrick Roose, Kris Cooreman and Wilfried Vyncke, Fisheries Research Station (CLO, Gent), Ankerstraat 1, 8400 Oostende, Belgium.

\title{
1. Abstract
}

PCB levels in cod, flounder, mussel and shrimp, covering a ten year period, were assessed for temporal trends and their relation to biological parameters. A significant relation was demonstrated between the PCB levels on a wet weight basis and the total lipid content. Normalising on the lipid content reduced the differences in PCB levels between the organisms and between different tissues within the organism. A general downward trend was observed for the PCB levels on the Belgian continental shelf.

\section{Introduction}

Polychlorinated biphenyls (PCBs) are ubiquitous environmental contaminants which have been a major reason for intemational concern since the discovery of their presence in the environment by Jensen ". Their widespread occurrence in the marine environment and their toxic potential resulted in a number of international monitoring programmes such as the Co-ordinated Monitoring Programme of the International Council for the Exploration of the Seas (ICES) and the Joint Monitoring Programme (JMP) of the Oslo and Paris Commissions (OSPARCOM) ${ }^{2)}$. These programmes aimed to assess the levels of PCB contamination in the marine environment with emphasis on human consumption and the overall quality of the marine ecosystem, and to investigate possible trends in PCB levels.

The Belgian Fisheries Research Station is measuring PCBs in marine samples since 1978. The data presented here cover an eleven years' period (1983-1993) and form a solid basis to investigate time trends. Trends in the PCB concentrations in cod, flounder, mussel and shrimp on the Belgian continental shelf in relation to biological parameters such as fat content, age, weight, length and sex are assessed.

\section{Methods}

Sampling

Cod (Gadus morhua), flounder (Platichthys flesus) and shrimp (Crangon crangon) were collected by the institute, using beam trawling, on the Belgian continental shelf from 1983 to 1993 . Twenty-five individuals per fish species were sampled 2-3 months prior to spawning and divided in five length classes between 214 and $905 \mathrm{~mm}$ for cod and 200 and $450 \mathrm{~mm}$ for flounder. Muscle tissue was analysed individually but livers were pooled per length class. Shrimp sample sizes comprised 100 individuals. Cooked tail muscle was isolated and divided in five subsamples. Mussels (Mytilus edulis) were harvested on three jetties along the Belgian coast and sorted per length class of $20-30 \mathrm{~mm}, 30-40$ $\mathrm{mm}, 40-50 \mathrm{~mm}$ and $>50 \mathrm{~mm}$. Total sample sizes were between 150 and 617 individuals. The mussels were left in settled sea water at room temperature for 24 hours. Subsequently the soft body was isolated for analysis. All samples were stored at $-28{ }^{\circ} \mathrm{C}$ prior to analysis. 


\section{Chemical analysis}

Extraction was based on total lipid extraction according to the method of Bligh and Dyer ${ }^{31}$. The extracted lipids firstly used for the determination of the fat content were redissolved in hexane, and the resulting solution was subsequently cleaned on a florisil ${ }^{4)}{ }^{5)}$. Analysis was performed using capillary gas chromatography with electron capture detection. Prior to 1989, the PCB concentrations were calculated on the basis of comparison with 8 PCB peaks of Aroclor ${ }^{4)}$. These eight peaks corresponded with IUPAC nrs. 101, 136, 147, 153, 138, 128, 180 and $170^{\circ}$ ). Concentrations of individual congeners, viz. IUPAC $n^{\circ} 28,31,52,101,105,118,138,153,156$ and $180^{6}$ ), are determined since $1989^{5)}$. Prior to 1990 quality assurance consisted of the analysis of procedural blanks, reproducibility and repeatability tests, injection of standard solutions as unknowns and analysis of samples with known concentrations. Since 1990 the analysis of a certified reference material (BCR CRM 349) was added to the above list as a standard procedure.

Cod

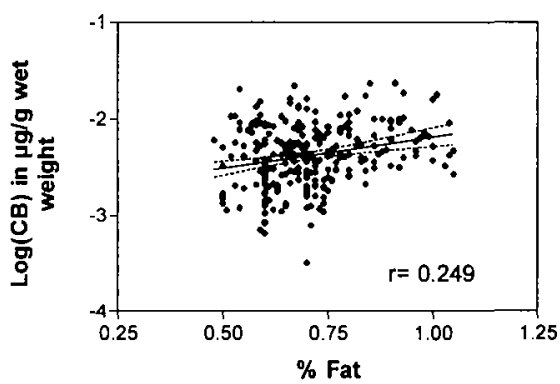

Mussel

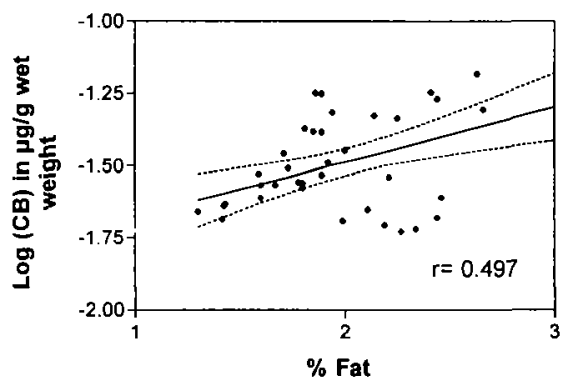

Flounder

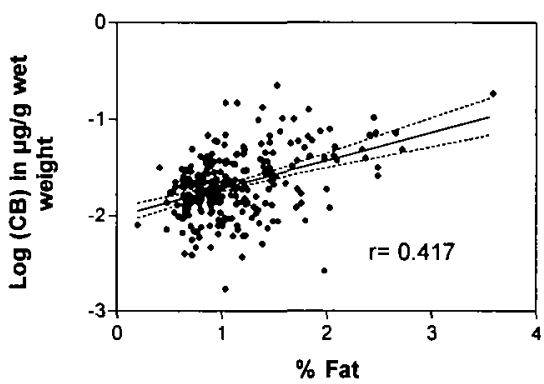

Shrimp

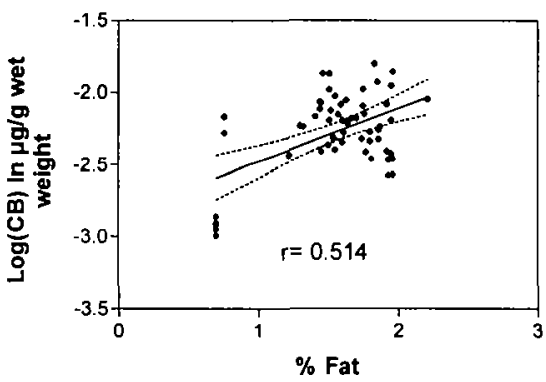

Figure 1 Relationship between the fat content and $\log (\mathrm{PCB})$ expressed on a wet weight basis ( $\mathrm{r}=$ correlation coefficient, dotted line $=95 \%$ confidence interval)

\section{Statistical analysis}

All statistical analyses were performed on total PCB concentration and the significancy level was set at minimum 95\%. Correlations between fat content, length of the animal and PCBs were analysed by linear regression. The non-parametric Mann-Withney test was used to investigate the relation between sex and PCB concentrations; and the non-parametric Kruskall-Wallis ANOVA test combined with Dunns' post test was performed to compare the PCB contents of liver and muscle tissues in and among species and to investigate the influence of the age of the animals on the PCB content. Time- 


\section{ECOTOX I}

trend analysis of the PCB concentrations (median values per year) in cod, flounder and mussel were investigated according to the method of Nicholson et al. ${ }^{\text {) }}$. PCB trends in shrimp were analysed by linear regression.

\section{Results}

Relation between the $P C B$ concentration and the fat content.

Fig. 1 illustrates the relation between fat content and $\log \left(\sum \mathrm{PCB}\right)$, both on wet weight basis for cod, flounder, blue mussel and brown shrimp. A significant correlation is present between the $\log \left(\sum \mathrm{PCB}\right)$ expressed on a wet weight basis and the fat content. In contrast, no correlation could be demonstrated between $\log \left(\sum \mathrm{PCB}\right)$ expressed on a fat weight basis and the fat content. Fig 2 illustrates the effect of lipid normalisation of the PCB data for all species and tissues examined. The results of Kruskal-Wallis ANOVA analysis of the data indicate significant $(\mathrm{P}<0.001)$ inter-tissue and inter-species differences. However, narrowing this down with Dunn's post test revealed that the differences between cod liver, flounder liver, flounder muscle and blue mussel (soft body tissue) became non-significant. It can therefore be concluded that normalisation on the lipid content clearly reduced the differences between organisms and tissues.

A

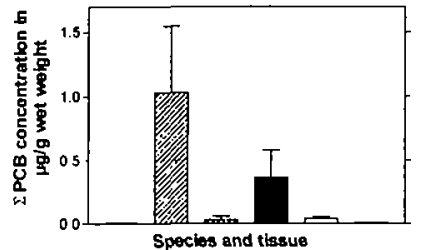

$\mathbf{B}$

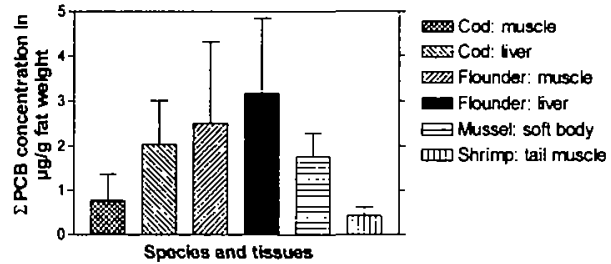

Figure 2 PCB concentration on (A) wet weight and (B) fat weight for cod flounder, mussel and shrimp.

Relations between the $\Sigma P C B$ concentrations and size, sex and age.

The trend analysis of Nicholson et al. ${ }^{7)}$ dictates a different approach when a size effect is established. Fig. 3 illustrates the relations between length and the PCB concentration. No demonstrable size effects on the $\sum \mathrm{PCB}$ concentrations in the tissues and species could be shown except in cod liver, especially in those animals ranging in size over $60 \mathrm{~cm}$. In addition to body size, the $\Sigma$ PCB concentrations were, when possible, also related to sex and age, but no significant relations could be demonstrated. These results confirm the assumption that the contaminant trend is not influenced by the animals' age- and sex-status.

\section{Temporal-trend analysis.}

The observed absence of relations between the PCB content and the animals' length, age or sex allowed the analysis of temporal trends in cod muscle, flounder muscle and flounder liver tissues and in blue mussel without statistical modifications, except in cod liver in which a length effect was demonstrated and in brown shrimp for which the length effect was not examined. The analysis of the cod liver data required a different approach. These data were subdivided into a "small" and a "large" group, both analysed independently ${ }^{7)}$. Temporal trends in brown shrimp data were analysed by linear regression. The temporal trends are illustrated in Fig. 3. Long-term changes in the PCB concentrations were only considered as significant within a $95 \%$ confidence interval . The results revealed (1) significant differences in cod and flounder muscle tissues and flounder liver tissue, (2) a significant downward non-linear trend in cod muscle (Fig. 3.), (3) a significant downward linear trend in flounder 
muscle (Fig. 3) (4) no trend in blue mussel tissue, (5) a significant downward trend in brown shrimp (Fig. 3) and (6) no significant trends in cod and flounder liver tissues.

Cod: muscle

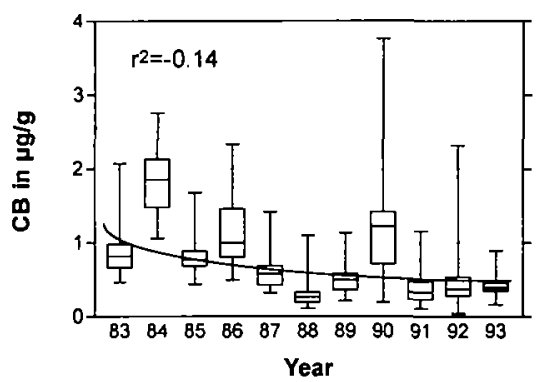

Flounder: muscle

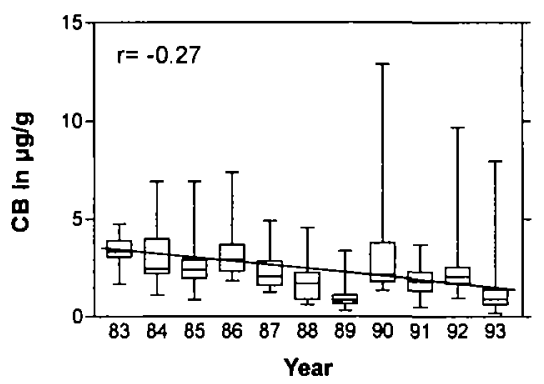

Mussel: soft body

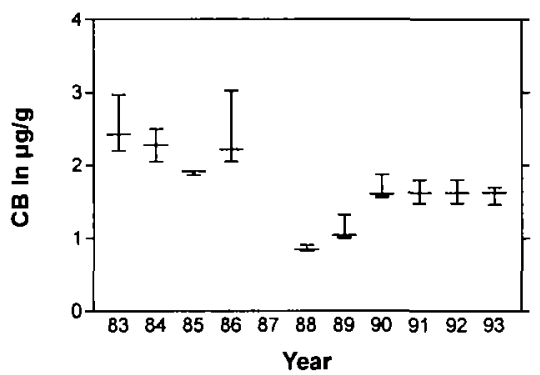

Cod: liver

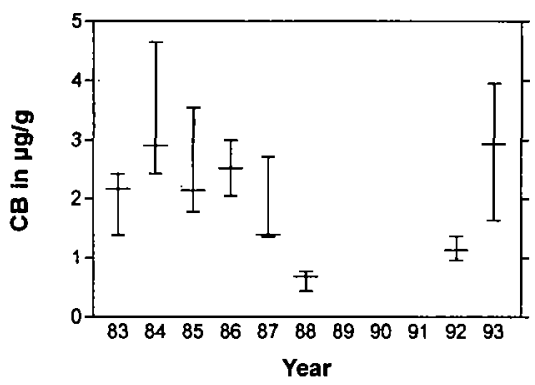

Flounder: liver

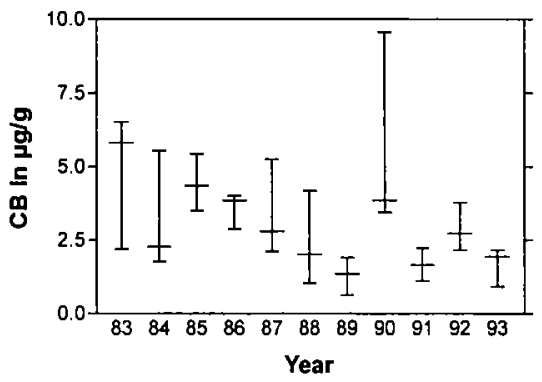

Shrimp

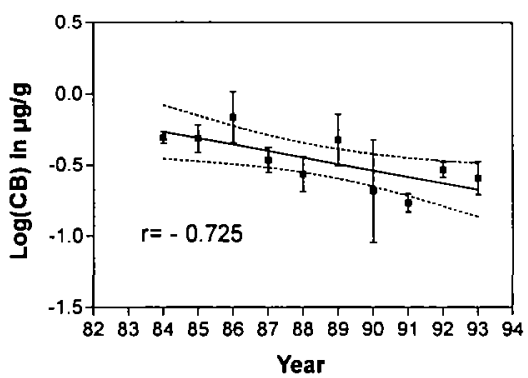

Figure 3 PCB concentrations in ug/g fat weight for cod, flounder and mussel (lines illustrate calculated significant trends, $r=$ correlation coefficient) and linear trend for the $\log (\mathrm{CB})$ concentration in shrimp.

\section{Conclusions}

PCB concentrations expressed on a wet weight basis show a significant correlation with the fat content. This finding agrees well with previous observations ${ }^{8)}$-11). Moreover, interspecies and tissuetype differences decreased when PCB concentrations were normalised for the fat content. The 
correlation between fat content and $\log (\Sigma \mathrm{PCB})$ illustrates the need for a normalisation of the $\mathrm{PCB}$ concentrations on lipid (fat) content, especially when a time trend assessment is envisaged. Natural variations in the lipid content of an organism or organ, due to spawning or starvation, may influence the variability of contaminant data when these data are expressed on a fresh (wet) weight basis.

Length, age and sex had no measurable effects on the PCB concentrations expressed on a lipid weight basis, with one exception : PCB concentrations in the liver of cod significantly increased with length (age). This finding therefore suggests that a significant biomagnification should only be expected for cod liver. An influence of the length of cod on the PCB content in the liver was previously reported by de Boer ${ }^{12)}$, who demonstrated a significant concentration difference between individuals of different sizes (53-54 cm and $85-91 \mathrm{~cm})$. Similarly, Kruse and Krüger ${ }^{13)}$ measured higher DDT levels in liver of Baltic cod with increasing animal size but did not notice similar trends for hexachlorobenzene (HCB), $\alpha$-hexachlorocyclohexane $(\alpha-\mathrm{HCH})$ and dieldrin. The presence of contaminants such as PCBs in poikilotherms is the result of a combination of uptake (directly from the water, ingestion of contaminated particles and food) and elimination (metabolisation, excretion, growth dilution). An explanation for the age-dependent biomagnification level in cod liver may be found in the regime of cod. Older cod mainly feed on fish, which is more contaminated than invertebrates that are preferably consumed by younger individuals ${ }^{14)}$. A major route of PCB uptake in older cod is therefore food and leads eventually to biomagnification. Nevertheless, the biomagnification in muscle tissue is not agedependent and might be related to different biological functions since cod mainly uses its liver as lipid deposition site. The uptake and elimination of PCBs appears to be more balanced in the other species and tissue-types sampled. In those cases no significant biomagnification could be demonstrated.

Significant downward trends were observed in muscle tissue of cod and flounder, and in shrimp, but not in mussel and the liver of both fish species. Flounder, blue mussel and brown shrimp are in that respect excellent indicator organisms that clearly reflect the quality status of their habitats because of no or restricted migrational activities. Cod has a more enhanced migrational pattern and does not necessarily reflect the condition of the area of capture. Nevertheless, cod is considered to be a suitable biomonitors for spatial and temporal trend monitoring ${ }^{15}$. The observed temporal trends in this study are on the same tenor as those recently reported. Decreasing PCB contents of several species and locations were cited in the 1993 North Sea Quality Status Report ${ }^{2)}$ and recent observations revealed lower chlorinated PCBs in yellow eel (Anguilla anguilla) from inland waters in The Netherlands ${ }^{16}$. PCB concentrations in cod (Gadus morhua) from the North Sea decreased significantly, while higher chlorinated congeners essentially remained at a constant level ${ }^{16)}$. The constancy of the PCB content of Mytilus edulis was also noticed by Stronkhorst ${ }^{17)}$ and by Solé et al. ${ }^{18)}$ in Mytilus galloprovincialis from the western Mediterranean Sea. The general downward trend could indicate that maximum PCB concentrations have been reached and that the compulsory remedial actions implemented by national and international organisations to improve the quality of the marine environment have become fruitful. However, although PCB concentrations have shown to decrease locally, a global decline should not be expected during the next years ${ }^{19}$ ), due to the ongoing inputs to the environment by a number of sources such as leakages from landfills and emissions from incinerators. Moreover, the quantities of PCBs still in use, still exceed the amount that has escaped into the environment ${ }^{19)}$.

\section{Acknowledgements}

The authors wish to thank Dr. J. de Boer, RIVO, DLO, Ijmuiden, the Netherlands, for his support and advice in the preparation of this article.

\section{References}

\footnotetext{
"Jensen, S. (1966): Report of a new chemical hazard. New Scientist 15, 612.

${ }^{21}$ North Sea Task Force. (1993): North Sea Quality Status Report 1993. Oslo and Paris Commissions, London. 132 pp.
} 
${ }^{3)}$ Bligh, E.G. and Dyer, W.J. (1959): A rapid method of total lipid extraction and purification for organic compounds. Can. J. Biochem. Physiol. 37, 911-917.

4) Vandamme, K. and Baeteman, M. (1982): Teneur des organismes marins des eaux cötières belges en PCB et en pesticides organochlorés. Revue de l'Agriculture 2, 1951-1958.

${ }^{51}$ Roose, P., Cooreman, K. and Vyncke, W. (1993): Correlation between EROD and GSH-T activities and the presence of organochlorines in the liver of dab from the Belgian continental shelf. International Council for the Exploration of the Seas (ICES), Kopenhagen, Denmark, E:15, 14 pp.

${ }^{6}$ Ballschmiter, K., Bacher, R., Mennel, A., Fisher, R., Riehle, U. and Swerev, M. (1992): The determination of chlorinated biphenyls, chlorinated dibenzodioxins and chlorinated dibenzofurans by GC-MS. J. High Resolut. Chromatogr. 15. 260-270.

7) Nicholson, M.D., Fryer, RJ. and Larsen, J.R. (1993): Revised Statistical Analysis of JMG Conaminant Trend Monitoring Data. International Council for the Exploration of the Seas (ICES), Kopenhagen, Denmark, MON 11/3/1-E:3, $20 \mathrm{pp}$.

${ }^{81}$ Schaefer, R.G., Emst, W., Goerke, H. and Eder, G. (1976): Residues of chlorinated hydrocarbons in North Sea animals in relation to biological parameters. Ber. Dt. Wiss. Komm. Meeresforsch. 24, 225-233.

${ }^{4)}$ Gocrke, H. Eder, G., Weber, K. and Ernst, W. (1979): Patterns of Organochlorine residues in animals of different trophic levels from the Weser Estuary. Mar. Poll. Bull. 10, 127-133.

${ }^{10)}$ Schneider, R. (1982): Polychlorinated biphenyls in cod tissues from the Western Baltic. Significance of equilibrium partitioning and lipid composition in the bioaccumulation of lipophilic pollutants in gill-breathing animals. Meeresforsch. 29, 69-79.

${ }^{11)}$ Delbeke, K.. Teklemariam. T., de la Cruz, E. and Sorgeloos, P. (1994): Reducing variability in pollution data: the use of lipid classes for normalisation of pollution data in marine biota. Int. J. Environ. Anal. Chem. (in press)

${ }^{12)}$ De Boer, J. (1994): Spatial differences and temporal trends of bioaccumulating halogenated hydrocarbons in livers of Atlantic cod (Gadus morhua) from the North Sea, 1977-1992. In Quality Status Report-Scientific Symposium, Ebeltoft Ed. by North Sea Task Force, London, UK, (in press).

${ }^{13)}$ Kruse and Krilger (1981): Organochlor-Pestizide in Dorshleber. Allg. Fischwirtschatsz.. 33. 168-169.

14) Daan, N. (1974): Growth of North Sea cod. Neth. J. Sea Res. 6, 479-517.

${ }^{15)}$ De Boer, J. and Brinkman, U.A.Th. (1994): The use of fish as biomonitors for the determination of contamination of the aquatic environment by persistent organochlorine compounds. Trends in Anal. Chem. 13, 397-404.

${ }^{16)}$ De Boer, J. (1995): Analysis and Biomonitoring of Complex Mixtures of Persistent Halogenated Micro-contaminants.

Ph.D. Thesis. Free University of Amsterdam, Amsterdam. 323 pp.

${ }^{17)}$ Stronkhorst, J. (1992): Trends in pollutants in blue mussel Mytilus edulis and Flounder Platichtys flesus from two Dutch estuaries, 1985-1990. Mar. Poll. Bull. 24, 250-258.

${ }^{18}$ Solé. M., Porte, C., Pastor, D. and Albaigés, J. (1994): Long-term trend of polychlorinated biphenyls and

organochlorinated pesticides in mussels from the westem Mediterranean coast. Chemosphere 21, 1063-1085.

${ }^{19)}$ Tanabe, S. (1988): P.B.C. Problems in the future : Foresight from current knowledge. Environ. Poll. 50, 5-28. 